\title{
The second-generation antipsychotic drug aripiprazole modulates the serotonergic system in pancreatic islets and induces beta cell dysfunction in female mice
}

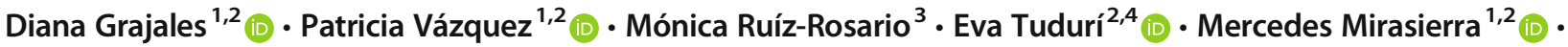 \\ Vítor Ferreira $^{1,2}$ (D) - Ana B. Hitos ${ }^{1,2}$ (D) - Dora Koller ${ }^{5}$ (D) Pablo Zubiaur ${ }^{5}$ (D) - Juan C. Cigudosa ${ }^{3}$. \\ Francisco Abad-Santos $^{5}$ (D) Mario Vallejo $^{1,2}$ (D) Iván Quesada $^{2,4}$ (D) Boaz Tirosh $^{6}$ (D) Gil Leibowitz $^{7}$ (D) \\ Ángela M. Valverde ${ }^{1,2}$ (D)
}

Received: 12 January 2021 / Accepted: 5 October 2021 / Published online: 21 December 2021

(C) The Author(s) 2021

\begin{abstract}
Aims/hypothesis Second-generation antipsychotic (SGA) drugs have been associated with the development of type 2 diabetes and the metabolic syndrome in patients with schizophrenia. In this study, we aimed to investigate the effects of two different SGA drugs, olanzapine and aripiprazole, on metabolic state and islet function and plasticity.

Methods We analysed the functional adaptation of beta cells in 12-week-old B6;129 female mice fed an olanzapine- or aripiprazole-supplemented diet $\left(5.5-6.0 \mathrm{mg} \mathrm{kg}^{-1} \mathrm{day}^{-1}\right)$ for 6 months. Glucose and insulin tolerance tests, in vivo glucosestimulated insulin secretion and indirect calorimetry were performed at the end of the study. The effects of SGAs on beta cell plasticity and islet serotonin levels were assessed by transcriptomic analysis and immunofluorescence. Insulin secretion was assessed by static incubations and $\mathrm{Ca}^{2+}$ fluxes by imaging techniques.

Results Treatment of female mice with olanzapine or aripiprazole for 6 months induced weight gain $(p<0.01$ and $p<0.05$, respectively), glucose intolerance $(p<0.01)$ and impaired insulin secretion $(p<0.05)$ vs mice fed a control chow diet. Aripiprazole, but not olanzapine, induced serotonin production in beta cells vs controls, likely by increasing tryptophan hydroxylase 1 (TPH1) expression, and inhibited $\mathrm{Ca}^{2+}$ flux. Of note, aripiprazole increased beta cell size $(p<0.05)$ and mass $(p<0.01)$ vs mice fed a control chow diet, along with activation of mechanistic target of rapamycin complex 1 (mTORC1)/S6 signalling, without preventing beta cell dysfunction.

Conclusions/interpretation Both SGAs induced weight gain and beta cell dysfunction, leading to glucose intolerance; however, aripiprazole had a more potent effect in terms of metabolic alterations, which was likely a result of its ability to modulate the serotonergic system. The deleterious metabolic effects of SGAs on islet function should be considered while treating patients as these drugs may increase the risk for development of the metabolic syndrome and diabetes.
\end{abstract}

Keywords Beta cell dysfunction · Beta cell mass · Insulin secretion · Islets · Schizophrenia · Second-generation antipsychotics · Type 2 diabetes

Ángela M. Valverde

avalverde@iib.uam.es

1 Instituto de Investigaciones Biomédicas Alberto Sols, Consejo Superior de Investigaciones Científicas (CSIC), Madrid, Spain

2 CIBER de Diabetes y Enfermedades Metabólicas Asociadas (CIBERDEM), Instituto de Salud Carlos III, Madrid, Spain

3 NIMGenetics, Madrid, Spain
4 Instituto de Investigación, Desarrollo e Innovación en Biotecnología Sanitaria de Elche (IDiBE), Universidad Miguel Hernández, Elche, Spain

5 Clinical Pharmacology Department, Hospital Universitario de La Princesa, Instituto de Investigación Sanitaria La Princesa, Madrid, Spain

6 The Institute of Drug Research, The Hebrew University of Jerusalem, Jerusalem, Israel

7 Endocrinology and Metabolism Service, Department of Medicine, Hadassah-Hebrew University Medical Center, Jerusalem, Israel 


\section{Research in context}

\section{What is already known about this subject?}

- Second-generation antipsychotic (SGA) drugs are the first-line treatment for schizophrenia because of their clinical efficacy and reduced extrapyramidal side effects

- SGAs have been associated with severe metabolic alterations, including impairment of whole-body glucose homeostasis and body weight gain, which can increase the risk of type 2 diabetes

- Some SGAs are more diabetogenic than others, i.e. olanzapine or clozapine, while others, such as aripiprazole, are considered to be less diabetogenic

\section{What is the key question?}

- How does SGA treatment affect pancreatic beta cell function and islet plasticity?

\section{What are the new findings?}

- In mice, both olanzapine and aripiprazole induced glucose intolerance and reduced insulin secretion

- Aripiprazole modulates the serotonergic system in mouse islets, inducing mechanistic target of rapamycin (mTOR)/S6 phosphorylation, tryptophan hydroxylase 1 (TPH1) expression and serotonin production in beta cells

- The effects of olanzapine on insulin secretion seem to be independent of the serotonergic system

\section{How might this impact on clinical practice in the foreseeable future?}

- A better understanding of the mechanisms by which SGAs induce beta cell dysfunction could pave the way for preventing type 2 diabetes in patients with schizophrenia who are administered these drugs

\begin{tabular}{|c|c|}
\hline \multicolumn{2}{|c|}{ Abbreviations } \\
\hline $\mathrm{D} 2 \mathrm{R}$ & Dopamine D2 receptor \\
\hline D3R & Dopamine D3 receptor \\
\hline D4R & Dopamine D4 receptor \\
\hline DEGs & Differentially expressed genes \\
\hline $\mathrm{EE}$ & Energy expenditure \\
\hline$\Delta \mathrm{F}$ & Change in fluorescence \\
\hline $\mathrm{F}_{\text {basal }}$ & Basal fluorescence \\
\hline GSIS & Glucose-stimulated insulin secretion \\
\hline $\mathrm{H}_{1} \mathrm{R}$ & Histamine $\mathrm{H}_{1}$ receptor \\
\hline $5-\mathrm{HT}$ & 5-Hydroxytryptamine \\
\hline iWAT & Inguinal white adipose tissue \\
\hline M1R & Muscarinic M1 receptor \\
\hline M5R & Muscarinic M5 receptor \\
\hline mTOR & Mechanistic target of rapamycin \\
\hline mTORC1 & Mechanistic target of rapamycin complex 1 \\
\hline ORA & Over-representation analysis \\
\hline$p$-adj & Adjusted $p$ value \\
\hline PCA & Principal component analyses \\
\hline PCPA & 4-Chloro-DL-phenylalanine \\
\hline RER & Respiratory exchange ratio \\
\hline RNA-seq & RNA-sequencing \\
\hline RT-qPCR & Quantitative real-time PCR \\
\hline SGA & Second-generation antipsychotics \\
\hline TEM & Transmission electron microscopy \\
\hline TPH1 & Tryptophan hydroxylase 1 \\
\hline WAT & White adipose tissue \\
\hline
\end{tabular}

\section{Introduction}

In recent years, an increased incidence of type 2 diabetes in patients taking chronic pharmacological treatment has been reported [1]. In patients receiving second-generation antipsychotic (SGA) drugs $[2,3]$, the first-line treatment for schizophrenia, the increase in incidence varies between $10 \%$ and $20 \%$. SGAs induce metabolic alterations, including weight gain, hyperglycaemia, insulin resistance and dyslipidaemia, which increase the risk for cardiovascular disease [2]. In a large cohort of drug-naive individuals with schizophrenia, the incidence of type 2 diabetes was augmented in those prescribed the SGA olanzapine [4]. Rajkumar et al reported that the SGAs olanzapine and aripiprazole doubled the risk for developing type 2 diabetes, whereas the first in class antipsychotic, clozapine, increased the risk by fourfold [5]. Female individuals are more susceptible to the metabolic side effects of SGAs and, therefore, preclinical studies are often performed on female rodents [6].

SGAs act through a broad range of receptors, including dopamine D1-D4 receptors (D1R-D4R), serotonin receptors (5-hydroxytryptamine [5-HT] $)_{1 \mathrm{~A}}, 5-\mathrm{HT}_{2 \mathrm{~A}}, 5-\mathrm{HT}_{2 \mathrm{C}}, 5-\mathrm{HT}_{3}, 5$ $\mathrm{HT}_{6}$ and $\left.5-\mathrm{HT}_{7}\right)$, histamine $\mathrm{H}_{1}$ receptor $\left(\mathrm{H}_{1} \mathrm{R}\right)$ or muscarinic M1-M5 receptors (M1R-M5R) [7]. Several studies have tested SGA drug-induced effects on whole-body glucose homeostasis [8]; however, their impact on beta cell function remains unclear [9]. Beta cells express different serotonergic receptors 
and synthesise, store and release serotonin in response to glucose, but the effects of SGAs on serotonin biosynthesis and signalling in islets and their impact on insulin secretion are not clear [10]. As reviewed previously [8], olanzapine has higher antagonistic activity against serotonin $5-\mathrm{HT}_{2 \mathrm{~A}}$ receptors and the dopamine receptor D2R, but is also antagonistic against D3R and D4R, 5- $\mathrm{HT}_{3}$ and 5- $\mathrm{HT}_{6}$ receptors, $\mathrm{H}_{1} \mathrm{R}, \alpha 1-$ adrenergic receptors and M1R-M5R. On the other hand, aripiprazole has partial agonistic activity for the dopamine receptors D2R, D3R and D4R, $5-\mathrm{HT}_{1 \mathrm{~A}}$ and $5-\mathrm{HT}_{2 \mathrm{C}}$ receptors, and $\alpha 1$-adrenergic receptors, and also exhibits $5-\mathrm{HT}_{2 \mathrm{~A}}$ and 5$\mathrm{HT}_{7}$ receptor antagonism.

Herein, we used the chemically unrelated SGAs, olanzapine (a commonly prescribed SGA that is highly diabetogenic) and aripiprazole (the metabolic side effects of which are less well-known) to study the effects of prolonged treatment with SGAs on blood glucose levels, islet morphometry and beta cell function in female mice.

\section{Methods}

Animals Animal experiments were approved by the Animal Ethics Committees of the Spanish National Research Council and Comunidad de Madrid in accordance with Spanish (RD 53/2013) and European Union (63/2010/EU) legislation (PROEX 037/17).

Details of the B6;129 mice used in this study have been previously reported [11]. Mice were housed in a pathogen-free facility in temperature-, humidity- and light-controlled rooms (with a $12 \mathrm{~h}$ light-dark cycle), with free access to food and water. Ninety female mice, aged 12 weeks, were randomly allocated into three experimental groups; mice received a standard chow diet (SAFE A04; Scientific Diets [SAFE], France), or the same diet supplemented with olanzapine (GP8311; Glentham Life Sciences, UK) or aripiprazole (AC457990010; ACROS Organics, ThermoFisher Scientific, USA) (both $40 \mathrm{mg} / \mathrm{kg}$ chow diet). Dosage (5.5-6.0 $\mathrm{mg} \mathrm{kg}^{-1}$ day $^{-1}$ ) was calculated considering daily food intake. After 6 months on the diet, mice were euthanised by cervical dislocation and pancreatic islets, whole pancreases, white adipose tissue (WAT) depots (epididymal WAT [eWAT] and inguinal WAT [iWAT]) and blood were collected and processed for analysis. As a positive control for serotonin expression in islets we used 12-day pregnant B6 female mice, aged 16 weeks, bred in-house with B6 male mice.

Analysis of olanzapine and aripiprazole in plasma A simple and sensitive LC-MS/MS method (Agilent Technologies, Spain) was used for simultaneous determination of aripiprazole and olanzapine levels in plasma, as reported previously [12] and detailed in the electronic supplementary material (ESM) Methods.
Food intake measurement Food intake was measured manually using KERN PCB2500-2 scales (KERN, Germany) during the first month of treatment in mice housed in group cages and the mean food intake per mouse and per day was calculated.

Metabolic assays After 6 months on the diets, metabolic assays were performed, including i.p. GTT, i.p. ITT, glucose-stimulated insulin secretion (GSIS) and indirect calorimetry (see ESM Methods). In brief, for GTT and GSIS analysis, after $16 \mathrm{~h}$ of fasting, D-(+)-Glucose ( $2 \mathrm{~g} / \mathrm{kg}$ body weight; G8270; Sigma-Aldrich, USA) was injected into mice and tail vein blood samples were collected at $0-120$ min post-injection. For ITTs, after $4 \mathrm{~h}$ of fasting, human recombinant insulin (Actrapid; $0.75 \mathrm{U} / \mathrm{kg}$ body weight; Novo Nordisk, Denmark) was injected into mice and tail vein blood samples were collected at 0-90 min post-injection. Plasma glucose and insulin levels were measured via glucometer (Accu-Check Aviva; Roche Diagnostics, Switzerland) and ELISA (10-1247-01; Mercodia, Sweden), respectively. Indirect calorimetry analysis was carried out during light and dark cycles using the TSE Phenomaster monitoring system (TSE Systems, Germany). Oxygen consumption and $\mathrm{CO}_{2}$ release were measured, and respiratory exchange ratio (RER) was determined as $\dot{V} \mathrm{CO}_{2}$ $/ \mathrm{O}_{2}$. Energy expenditure $(\mathrm{EE})$ was calculated as $\mathrm{EE}=(3.185$ $+1.232 \times \mathrm{RER}) \times \dot{V} \mathrm{O}_{2}$. Total locomotor activity was simultaneously measured using an infrared photocell beam interruption method, carried out using the TSE Phenomaster, as described previously [13]. Analysis was performed using the TSE Phenomaster Mouse software V5.1.7 (TSE Systems).

Pancreatic islet isolation and culture Islets were isolated by collagenase P (11215809103; Roche, Germany) digestion (13.5 U/ml in cold Hank's buffer), as described previously [14]. For ex vivo experiments, islets were recovered overnight at $37^{\circ} \mathrm{C}$ and $5 \% \mathrm{CO}_{2}$ in complete RPMI-1640 medium ( $2 \mathrm{mmol} / 1 \mathrm{~L}$-glutamine, $1 \mathrm{mmol} / 1$ sodium pyruvate, $50 \mu \mathrm{mol} /$ $1 \beta$-mercaptoethanol, $10 \mathrm{mmol} / \mathrm{l} \mathrm{HEPES}$ and $10 \%$ [vol./vol.] FBS) containing $5.6 \mathrm{mmol} / \mathrm{l}$ glucose. The next day, islets were pooled, randomised and incubated with $6 \mu \mathrm{mol} / \mathrm{l}$ olanzapine or aripiprazole (dissolved in DMSO; D8418; Sigma-Aldrich), 1-500 $\mu \mathrm{mol} / 1$ serotonin (14927; Sigma-Aldrich) (1-24 h incubation) or $10 \mu \mathrm{mol} / 1$ 4-Chloro-DL-phenylalanine (PCPA; C6506; Sigma-Aldrich). Control islets were treated with $0.01 \%$ (vol./vol.) DMSO.

Static incubations For each individual mouse, 3-6 groups of three islets matched by size were placed in each well of a 96well plate. Islets were pre-incubated for $1 \mathrm{~h}$ at $37^{\circ} \mathrm{C}$ and $5 \%$ $\mathrm{CO}_{2}$ in $\mathrm{KRB}$ containing $2.8 \mathrm{mmol} / 1$ glucose, $115 \mathrm{mmol} / \mathrm{l}$ $\mathrm{NaCl}, 5 \mathrm{mmol} / \mathrm{l} \mathrm{KCl}, 1.2 \mathrm{mmol} / 1 \mathrm{NaHCO}_{3}, 1.1 \mathrm{mmol} / \mathrm{l}$ $\mathrm{MgCl}_{2}, 1.2 \mathrm{mmol} / 1 \mathrm{NaH}_{2} \mathrm{CO}_{4}, 2.5 \mathrm{mmol} / 1 \mathrm{CaCl}_{2}, 25 \mathrm{mmol} / \mathrm{l}$ 
HEPES and $0.25 \%$ (wt/vol.) BSA. Incubations were then performed using $2.8 \mathrm{mmol} / 1$ or $16.7 \mathrm{mmol} / 1$ glucose at $37^{\circ} \mathrm{C}$, $5 \% \mathrm{CO}_{2}$ for $1 \mathrm{~h}$. Insulin levels were determined by ELISA (Mercodia) and values were normalised to islet number.

Insulin content Insulin was extracted from 20 islets/mice using glycine/NP-40 lysis buffer $(200 \mathrm{mmol} / 1$ glycine, $0.5 \%$ NP-40; $\mathrm{pH} 8.8$ ) and measured by ELISA.

Intracellular $\mathrm{Ca}^{2+}$ imaging Islets treated ex vivo with SGAs were pre-incubated with Fura-2 AM (F11212; ThermoFisher Scientific) and perfused with KRB containing glucose ( $2.8 \mathrm{mmol} / \mathrm{l}$ or $16.7 \mathrm{mmol} / \mathrm{l})$. Fluorescence measurements were obtained at excitation wavelengths of $340 \mathrm{~nm}$ and $380 \mathrm{~nm}$ with an Axiovert 200 inverted microscope (Zeiss, Germany) with appropriate filters. Data acquisition was performed with the Aquacosmos 2.6 software (Hamamatsu Photonics, Japan). Recordings were expressed as the ratio of fluorescence at $340 \mathrm{~nm}$ and $380 \mathrm{~nm}(\mathrm{~F} 340 / 380)$.

Immunohistochemistry Pancreases were fixed in Bouin's solution (HT10132; Sigma-Aldrich) overnight at $4^{\circ} \mathrm{C}$. Paraffin embedding and tissue sectioning were performed as described previously [15]. Longitudinal pancreatic sections of $6 \mu \mathrm{m}$ thickness, generated every $80 \mu \mathrm{m}$, were hydrated and pre-treated by boiling for $20 \mathrm{~min}$ in a microwave in antigen-retrieval solution containing $100 \mathrm{mmol} / \mathrm{l}$ sodium citrate dehydrate $(\mathrm{pH} 6$; W302600; Sigma-Aldrich) supplemented with $0.05 \%$ (vol./ vol.) Tween-20. Insulin and glucagon expression was analysed by immunohistochemistry staining using primary antibodies against insulin and glucagon, and secondary biotinylated antibodies diluted in PBS (ESM Table 1). Pancreatic sections were then processed for diaminobenzidine (DAB)-immunoperoxidase staining (SK-4100; Vector Laboratories, USA) and counterstained with Mayer's Hematoxylin (H3136; Sigma-Aldrich). Images were examined using a Axiophot Zeiss light microscope and captured with a DP70 digital camera (Olympus, Japan). Insulin and glucagon staining and total pancreatic area were quantified by ImageJ software version 1.52a (NIH, USA). Morphometric analysis of the pancreas is described further in ESM Methods.

Immunofluorescence of pancreatic sections and islets Pancreatic sections were processed as described above using antibodies against insulin, glucagon, serotonin, p-S6 and Ki67, and secondary Alexa-Fluor conjugated antibodies (see ESM Methods for further details). For in toto islet immunostaining, 20 islets were handpicked, placed in $\mu$-Slide 8 -well plates (80826; Ibidi, Germany) and processed for insulin and serotonin immunostaining, as detailed in ESM Methods. Antibody details are listed in ESM Table 1. Immunofluorescence was examined using an epifluorescence microscope (Nikon 90i; Olympus) and images were taken with a digital camera
(Nikon DS-2Mv, Japan). The percentage of beta cells coexpressing insulin and Ki67, p-S6 or serotonin was obtained by dividing the number of positive cells for each staining by the total number of insulin-positive cells in each islet.

Ultrastructural analysis by transmission electron microscopy For transmission electron microscopy (TEM) analysis, pools of 300 pancreatic islets from three mice per condition were processed as described in ESM Methods. Tissue sections were examined using a Zeiss Libra 120 transmission electron microscope and TEM images were taken with an electron multiplying charge coupled device (EMCCD) camera (Albert Tröndle, Germany). The number and type of the secretory granules in beta cells ( $n=10$ beta cells from three independent mice/group) were assessed using ImageJ software (NIH). Insulin granules from beta cells were classified into four categories: mature (with an electron-dense core); immature (with a less electron-dense core); empty (lacking the core); and atypical (insulin granules with an irregular shape).

Serotonin measurement Supernatants collected from static incubation experiments were used for the measurement of serotonin levels using the ELISA Fast Track kit (BA E-8900; LDN, Germany). Values were normalised to islet number.

Transcriptomic analysis of islets from treated mice by RNAsequencing Islets were isolated in TRIzol (15596026; ThermoFisher Scientific) and total RNA was extracted using the PureLink RNA Mini Kit (Invitrogen, USA). Total RNA expression was analysed using Illumina TruSeq Stranded RNASeq technology (Illumina, USA). The libraries were sequenced $(2 \times 100 \mathrm{bp})$ with a mean output of 40 million reads in a NovaSeq 6000 sequencer (Illumina). After a quality control check with FastQC (www.bioinformatics.babraham. ac.uk/projects/fastqc, access date 27 May 2019), the reads were aligned to reference transcripts with the Kallisto algorithm [16], which provides a matrix of estimated counts per transcript as the output. Exploratory analyses included principal component analysis (PCA) and hierarchical clustering (HC). Transcriptomic analyses were performed with the DESeq2 package [17], for which differentially expressed genes (DEGs) were described as those with an adjusted $p$ value ( $p$-adj) of $<0.1$ when performing a Wald test between two conditions and a Benjamini-Hochberg adjustment. Overrepresentation analyses (ORAs) of the DEGs were completed with the WEB-based GEne SeT AnaLysis Toolkit (WebGestalt) [18].

Western blotting Protein levels were assessed in pancreatic islets using antibodies against IRS-2, mechanistic target of rapamycin (mTOR), p-mTOR (Ser2448), S6K1, p-S6K1 (Thr389), p-S6 ribosomal protein, tryptophan hydroxylase 1 
(TPH1) and vinculin (ESM Table 1). Immunoreactivity was detected by chemiluminescence, using Clarity Western ECL Substrate (1705061; Bio-Rad, Germany). Densitometric analysis of the bands was performed using Image J software (NIH). The protocol is fully described in ESM Methods.

Quantitative real-time PCR Gene expression was determined by quantitative real-time PCR (RT-qPCR) using Power SYBR Green PCR Master Mix (4367659; ThermoFisher Scientific) and 7900HT Fast Real-Time PCR System (ThermoFisher Scientific), as described in ESM Methods. Primer sequences are shown in ESM Table 2.

Statistical analysis Statistical analysis was performed using Prism 8 (Graph software, USA). Datasets were first analysed for normal distribution. For data with parametric distributions, unpaired Student's $t$ test was used to compare mean differences between two groups, and for three or more groups, one-way ANOVA with Bonferroni post hoc test was used. For data with non-parametric distributions, differences between groups were examined with MannWhitney $U$ test for two groups, or Kruskal-Wallis test for three or more groups. Two-way ANOVA was employed to compare two different categorical, independent variables. Where other statistical analyses have been used, this has been indicated in the figure legends. Data are expressed as mean \pm SEM. Tests were two-sided and $p<0.05$ was considered statistically significant. Mice and islets were randomly and blindly distributed for the treatments by experimenters. Experimenters were not blind in outcome assessment.

\section{Results}

Alterations in body weight, adiposity, energy balance and glucose metabolism in female mice fed an antipsychotic drug-supplemented diet Female mice were fed an olanzapine- or aripiprazole-supplemented diet $(40 \mathrm{mg} / \mathrm{kg})$ for 6 months. Figure 1a,b shows plasma drug levels at the end of the treatment. Olanzapine-treated mice gained $8.70 \pm$ $0.88 \mathrm{~g}$ of body weight compared with a $4.90 \pm 0.47 \mathrm{~g}$ gain in controls fed a chow diet $(p<0.01)$. Aripiprazole-treated mice also gained more weight than the controls over the treatment period $(p<0.05)$ but, as body weight stabilised in the last month of the treatment in this group, there was less body weight gain compared with olanzapine-treated mice $(p>0.05)$ (Fig. 1c,d). Both olanzapine- $(p<0.01)$ and aripiprazoletreated $(p<0.001)$ mice had a significant increase in visceral adiposity and showed a slight, but not significant, increase in iWAT/body weight ratio vs controls (Fig. 1e,f).

We further studied the effects of the two SGAs on food intake. Consistent with a previous report [19], food consumption was higher in the olanzapine-treated group compared with the control group ( $p<0.05$; Fig. $1 \mathrm{~g}$ ), whereas no differences were found between aripiprazole-treated mice vs control or olanzapine-treated groups. EE and spontaneous locomotor activity were lower in the dark phase in olanzapineand aripiprazole-treated mice vs control mice, although this difference was only statistically significant for the aripiprazole-treated group vs controls ( $p<0.05$; Fig. 1h,i).

Fed and fasting blood glucose levels did not differ between groups (Fig. 1j, ESM Fig. 1b). However, fed plasma insulin levels were higher in mice receiving the olanzapine- $(p<0.01)$ or aripiprazole-supplemented diet $(p<0.05$; Fig. $1 \mathrm{k})$, whereas fasting insulin was similar between groups (ESM Fig. 1c), suggesting increased insulin resistance or impairment of insulin clearance with SGA treatment. We further assessed the effects of SGAs on glucose tolerance and insulin sensitivity. The GTT showed that olanzapine- and aripiprazole-fed mice developed glucose intolerance (Fig. 11). The ITT revealed that, although insulin sensitivity was reduced in both groups of treated mice, only the difference between the aripiprazoletreated and control groups was statistically significant $(p<0.01$; Fig. $1 \mathrm{~m})$. Collectively, these findings suggest that both SGAs induce alterations in glucose homeostasis, despite the fact that aripirazole treatment was associated with less weight gain.

Olanzapine and aripiprazole impaired beta cell function and altered islet morphology in female mice Olanzapine and aripiprazole treatment markedly impaired GSIS in vivo (AUC $p<0.05$; Fig. 2a), indicating impaired beta cell function. Consistently, ex vivo static incubations showed that GSIS was inhibited in islets of both olanzapine- $(p<0.01)$ and aripiprazole-treated animals $(p<0.05)$, as compared with islets from chow-diet-fed mice (Fig. 2b), without affecting islet insulin content (Fig. 2c).

To determine the mechanism underlying beta cell dysfunction in response to SGA treatment, islet morphometry was analysed (Fig. 2d-i). Islet size markedly increased in mice treated with olanzapine $(p<0.01)$ or aripiprazole $(p<0.001)$ vs controls (Fig. 2f). Beta cell mass was increased by twofold in aripiprazole-treated mice compared with chow-fed mice $(p<0.01)$, but this effect was not observed in olanzapinetreated mice (Fig. $2 \mathrm{~g}$ ). Interestingly, alpha cell mass was twofold higher in olanzapine-treated mice than in the controls (Fig. 2h), which was associated with a non-significant increase in alpha cell area without changes in islet cell composition (ESM Fig. 2). Comparative analysis of islet size distribution among groups confirmed the increased number of larger sized islets in mice treated with SGAs vs controls $(p<0.001$, analysed by $\chi^{2}$ test; Fig. 2i). Ultrastructural TEM analysis showed smaller numbers of mature insulin granules $(p=0.09)$ and more empty granules $(p=0.09)$ in beta cells from olanzapine-treated mice vs controls (ESM Fig. 2f). 

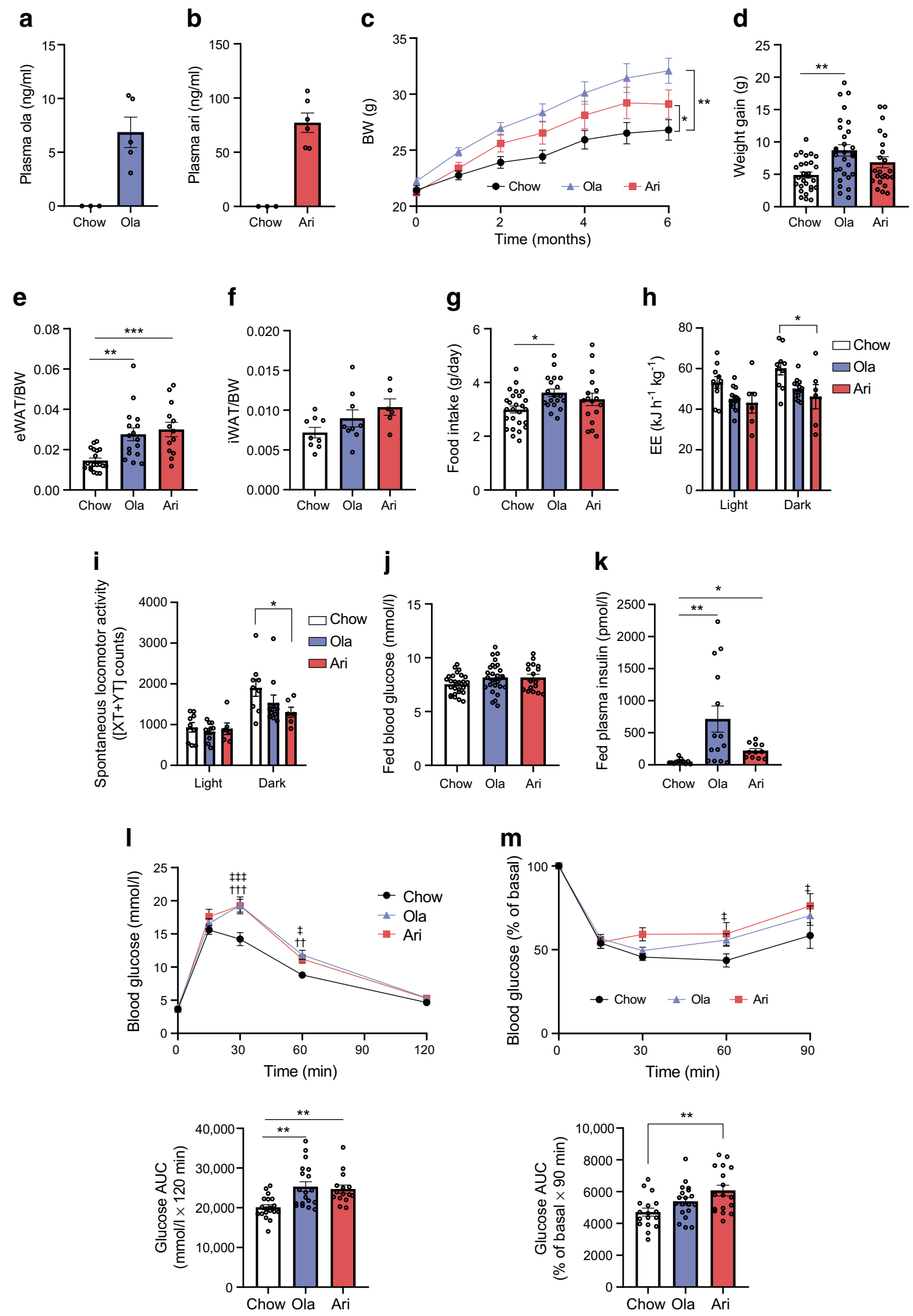

Effects of antipsychotic drug-supplemented diet on beta cell proliferation and size in female mice Consistent with a report in adult animals [20], beta cell proliferation, assessed by Ki67 immunostaining, was low and no differences were found 
Fig. 1 Effects of olanzapine (ola)- and aripiprazole (ari)-supplemented diet on body weight (BW), adiposity, energy balance and glucose metabolism in female mice. (a, b) Plasma levels of ola (a) and ari (b) in mice after 6 months of treatment with antipsychotic drug-supplemented diets ( $n=3-6$ mice/group). (c) BW monitored monthly and (d) BW gain in the last month of the treatment in mice fed an ari- or ola-supplemented $\operatorname{diet}(n=28$ control mice, $n=29$ ola-treated mice, $n=23$ ari-treated mice) (e) Epididymal WAT (eWAT) and (f) iWAT normalised to BW (n=6-19 mice/group). (g) Food intake during the first month of treatment ( $n=17-$ 26 mice/group). (h) EE and (i) locomotor activity (presented as [XY+YT] counts, indicating the total number of times mice cross the infrared sensors that border the measuring cage on the $\mathrm{X}$ and $\mathrm{Y}$ planes) measured at the end of the treatment period by indirect calorimetry ( $n=6-13 \mathrm{mice} /$ group). Light cycle: 08:00-20:00 hours; dark cycle: 20:00-08:00 hours. (j) Fed blood glucose (mmol/1) and (k) fed plasma insulin (pmol/l) levels ( $n=11-27$ mice/group). (l) i.p. GTT and the respective AUC ( $n=15-19$ mice/group). The AUC was calculated from 0 to $120 \mathrm{~min}$, according to the trapezoidal rule. (m) i.p. ITT and the respective AUC ( $n=17-19$ mice/group). The AUC was calculated from 0 to $90 \mathrm{~min}$, according to the trapezoidal rule. All data are presented as mean \pm SEM. $p$ values were determined by one-way $(\mathbf{d}, \mathbf{e}, \mathbf{f}, \mathbf{g}, \mathbf{j}, \mathbf{k}, \mathbf{l}$ (lower), $\mathbf{m}$ (lower)) or two-way (c, h, i, l (upper), $\mathbf{m}$ (upper)) ANOVA and Bonferroni post hoc test. $* p<0.05, * * p<0.01$, *** $p<0.001$ vs mice fed a chow diet; ${ }^{\dagger} p<0.01,{ }^{\dagger \dagger} p<0.001$, ola-treated mice vs mice fed a chow diet; ${ }^{\star} p<0.05,{ }^{4} p<0.001$, ari-treated mice vs mice fed a chow diet

between groups (Fig. 3a,b). Notably, beta cell size was increased in both olanzapine- and aripiprazole-treated mice $(p<0.05$; Fig. $3 c)$. mTOR complex 1 (mTORC1), a key regulator of cell size, plays an important role in beta cell compensation under stress conditions [21]. Immunostaining with an antibody against phosphorylated ribosomal protein S6, a downstream mTORC1 target, showed increased mTORC1 activity in beta cells from aripiprazole-treated mice $(p<0.05)$, but not from mice receiving olanzapine (Fig. 3d,e). Thus, mTORC1 might have a role in mediating beta cell compensation in aripiprazole-treated mice. Islets were then treated ex vivo with aripiprazole for $16 \mathrm{~h}$ and mTORC1 activity was assessed by western blotting for mTOR, S6K1 and S6 phosphorylation. Treatment with aripiprazole increased mTOR/S6K1/S6 phosphorylation (Fig. 3f), indicating stimulation of the mTORC1 signalling pathway.

\section{Ex vivo treatment of pancreatic islets with olanzapine and} aripiprazole impairs GSIS Ex vivo GSIS analyses showed that both olanzapine and aripiprazole used at $6 \mu \mathrm{mol} / 1$ reduced insulin secretion in islets without affecting insulin content (Fig. 4a,b), suggesting direct inhibitory effects of these drugs on insulin secretion.

We next analysed $\mathrm{Ca}^{2+}$ signalling in islets exposed ex vivo to olanzapine or aripiprazole for $24 \mathrm{~h}$. Islets treated with olanzapine showed a similar pattern of $\mathrm{Ca}^{2+}$ oscillations compared with control islets and no differences were found in the AUC/min, change in fluorescence $(\Delta F)$, basal fluorescence $\left(\mathrm{F}_{\text {basal }}\right)$ or response time to high glucose (time islets take to respond to change in glucose concentration by opening voltage-gated $\mathrm{Ca}^{2+}$ channels) vs controls (Fig. 4c,d,f, ESM Fig. 3a,c). By contrast, aripiprazole-treated islets exhibited attenuated $\mathrm{Ca}^{2+}$ entry, as reflected by decreased $\Delta \mathrm{F}$ and AUC/min, and delayed response to high glucose vs controls, while $\mathrm{F}_{\text {basal }}$ was similar between groups (Fig. 4e,g, ESM Fig. $3 b, d)$. These data suggest that aripiprazole interferes with $\mathrm{Ca}^{2+}$ signalling in beta cells.

Transcriptomic analysis in pancreatic islets from female mice fed an olanzapine- or aripiprazole-supplemented diet To identify the transcriptomic profile of mouse islets from SGA-treated mice we conducted RNA-sequencing (RNAseq). PCA showed differential gene expression in islets from mice under SGA treatment (Fig. 5a,b). DEGs were identified by DESeq 2 and classified as genes with $p$-adj $<0.1$ as assessed using a Wald test between two conditions with BenjaminiHochberg adjustment. Fifteen genes were differentially expressed in islets from olanzapine-treated mice and 244 genes were dysregulated in islets from aripiprazole-treated mice (ESM Table 3, ESM Table 4). Islets from mice receiving a chow diet were used to identify baseline gene levels.

We conducted ORA to address the specific genetic signatures associated with olanzapine or aripiprazole treatment. However, because 15 DEGs (in the case of olanzapine) is a small number of genes for ORA, the analysis was performed with all genes with a fold change $\leq-1.5$ or $\geq 1.5$ and a $p$ value $<0.05$, as assessed by the Wald test between two conditions, and relevant findings were further validated by RT-qPCR. A total of 289 genes dysregulated by aripiprazole and 136 by olanzapine were included in the ORA (data not shown). We found that the top-five upregulated pathways in the aripiprazole arm appeared to be related to serotonin biosynthesis (Fig. $5 \mathrm{~d}$ ). The heatmap of serotonin biosynthetic processes (gene set accession no.: GO:0042427, http://amigo.geneontology. org/amigo/term/GO:0042427/?q=DDC; access date 22 July 2019) shows that genes encoding the serotoninsynthetising enzymes Tph1 and Tph2 were upregulated in islets from aripiprazole-treated mice, whereas the gene encoding the Htr3a receptor was downregulated in islets of olanzapine-treated mice (Fig. 5e). Notably, transcriptional profiling showed no significant alterations in other genes related to islet function with SGA treatment (ESM Table 3, ESM Table 4). Figure 5 f shows the RT-qPCR analysis of common islet genes.

Effects of olanzapine and aripiprazole treatment on the expression of serotonin-related genes and serotonin levels in islets In agreement with RNA-seq data, RT-qPCR showed that aripiprazole increased Tph1 and Tph 2 expression vs controls ( $p<0.01$ and $p<0.05$, respectively; Fig. 6a), along with an apparent increase in TPH1 protein levels (Fig. 6b). In addition, the expression of the serotonin receptor Htr3a was 

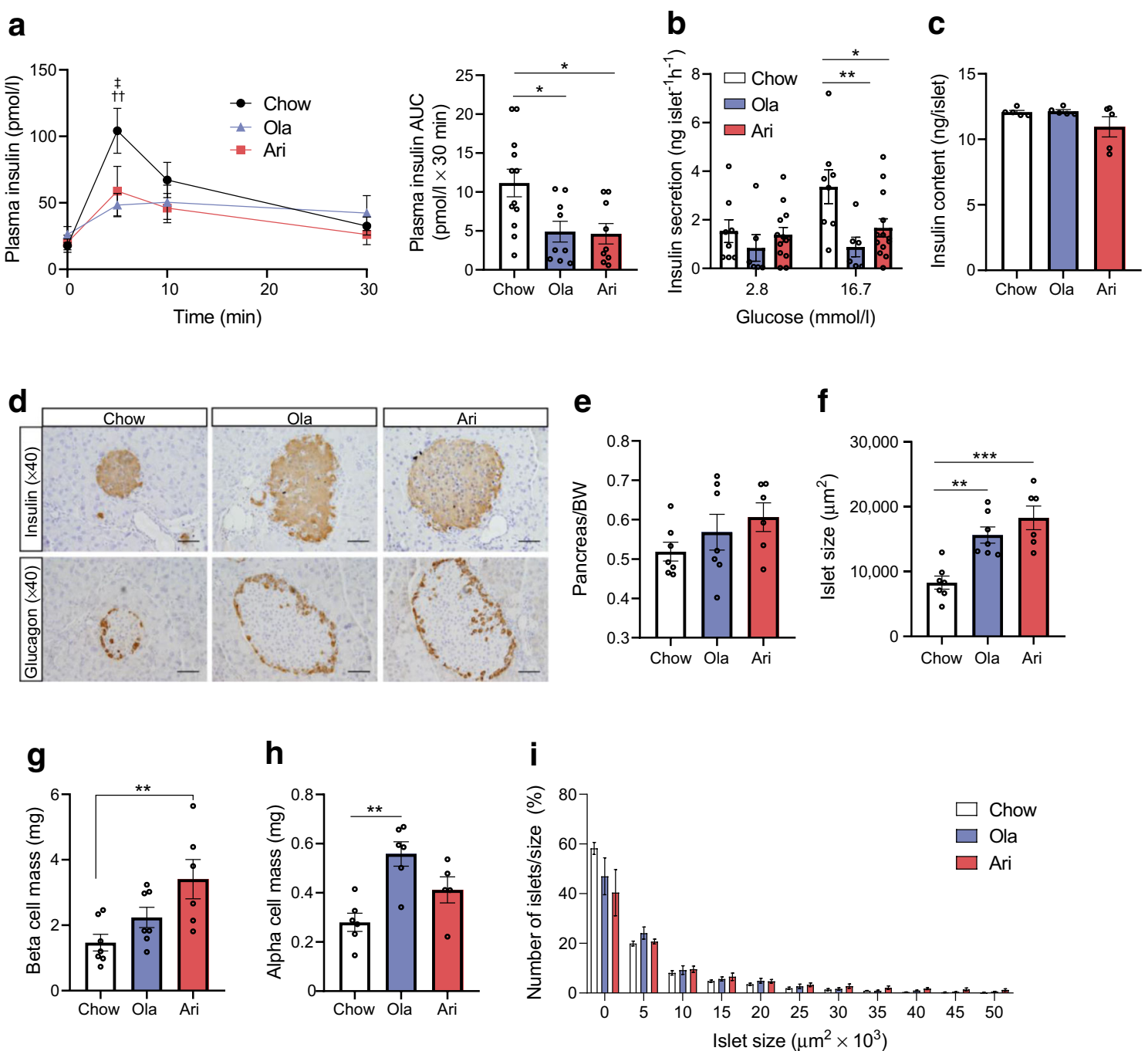

Fig. 2 Effects of olanzapine (ola)- or aripiprazole (ari)-supplemented diet on GSIS and islet morphology in female mice. (a) In vivo GSIS and the respective AUC, calculated from 0 to $30 \mathrm{~min}$ values, according to the trapezoidal rule ( $n=9-12$ mice/group). (b) Ex vivo GSIS, performed using 3-6 technical replicates for each condition and mouse $(n=6-13$ mice/group). Insulin secretion was corrected for islet number. (c) Insulin content in islets. Twenty islets per mouse were lysed and the insulin content was normalised to islet number ( $n=5 \mathrm{mice} / \mathrm{condition})$. (d) Representative images of pancreatic islets stained with insulin and glucagon; scale bars, $50 \mu \mathrm{m}$; magnification $\times 40$. (e) Pancreas weight normalised to body weight (BW). (f) Islet size $\left(\mu \mathrm{m}^{2}\right)$. (g) Beta cell mass (mg) ( $n=7$ control, $n=7$ ola-treated mice, $n=6$ ari-treated mice) and (h)

reduced in the olanzapine-treated group vs controls $(p<0.05$; Fig. 6c).

Serotonin has been implicated in beta cell compensation during pregnancy $[22,23]$. Ex vivo experiments showed higher serotonin secretion in islets from aripiprazole-treated mice, both with $2.8 \mathrm{mmol} / \mathrm{l}$ and $16.7 \mathrm{mmol} / \mathrm{l}$ glucose treatment, with findings being significant following exposure to $16.7 \mathrm{mmol} / 1$ glucose $(p<0.05$; Fig. 6d). Immunofluorescence images confirmed higher serotonin levels in islets from mice that received aripiprazole compared with control mice

alpha cell mass (mg) ( $n=6$ control, $n=6$ ola-treated mice, $n=5$ ari-treated mice). (i) Islet size distribution ( $n=7$ control, $n=7$ ola-treated mice, $n=6$ ari-treated mice). Between 8 and 12 pancreatic sections per mouse, generated every $80 \mu \mathrm{m}$, were analysed. At least 300 islets per mice were counted for determination of islet size. The differences between the distribution of islet size in ola- and ari-treated mouse samples were significant vs the distribution of islet size in samples from mice fed a chow diet $\left(p<0.001\right.$, by $\chi^{2}$ test). All data are presented as mean \pm SEM. $* p<0.05$, $* * p<0.01, * * * p<0.001$ vs mice fed a chow diet, by one-way ANOVA and Bonferroni post hoc test for the AUC graph in (a, right) and in (c, e, f, $\mathbf{g}, \mathbf{h})$ or by two-way ANOVA in (a, left, b); ${ }^{\dagger \dagger} p<0.01$, ola vs chow; ${ }_{p}{ }_{p<0.05}$, ari vs chow

$(p<0.01$; Fig. $6 \mathrm{e}, \mathrm{f})$. In fact, we observed that serotonin levels in islets from aripiprazole-treated mice appeared to be comparable with islets of pregnant mice (Fig. 6e). Overall, our findings indicate that aripiprazole treatment increased serotonin synthesis and secretion in islets.

Aripiprazole increases serotonin generation and induces TPH1 expression in pancreatic islets In light of the in vivo findings showing that aripiprazole treatment increased $T p h 1$ mRNA $(p<0.01)$ and that there was an apparent increase in 

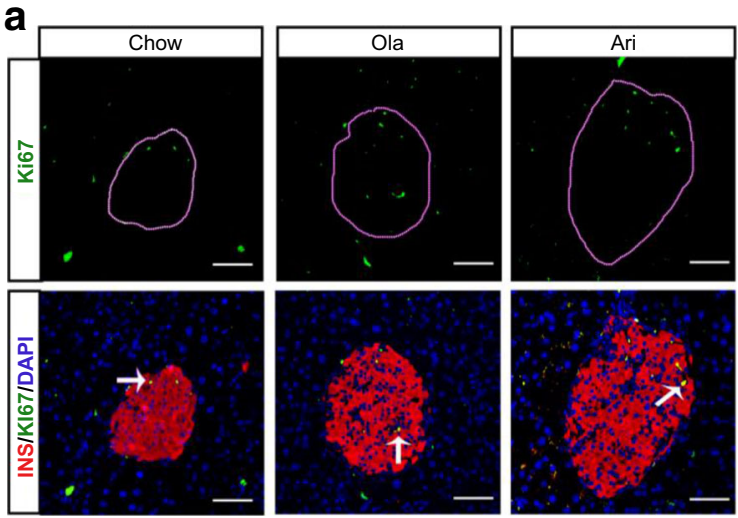

d
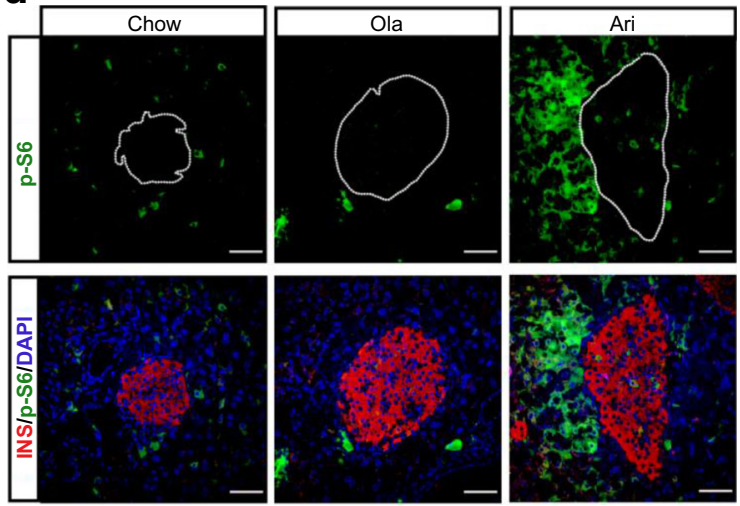

b

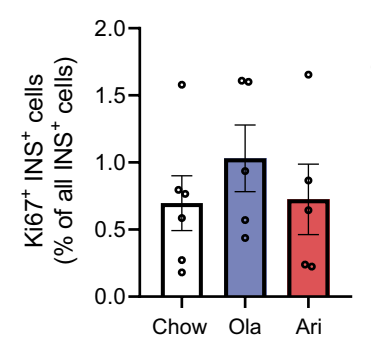

C

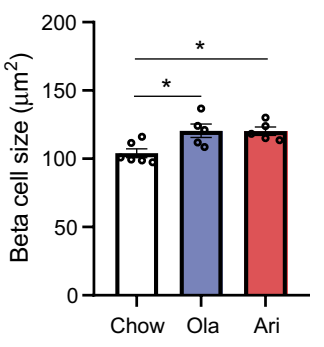

$\mathbf{f}$

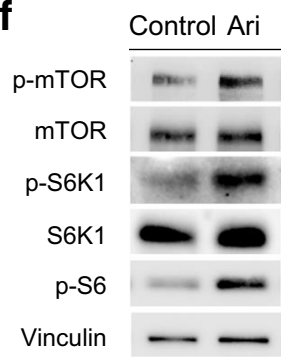

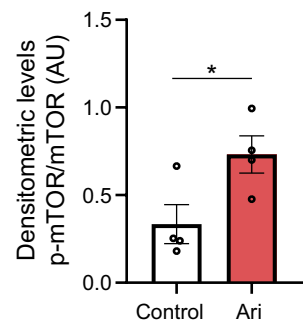

Fig. 3 Analysis of beta cell proliferation and size and phosphorylation of S6 ribosomal protein in islets from female mice after 6 months of treatment with an antipsychotic drug-supplemented diet. (a) Confocal images of Ki67 (green) immunofluorescence. Ki67 co-localisation with insulin (INS) $^{+}$cells (red) is indicated (white arrows); scale bars, $50 \mu \mathrm{m}$; magnification $\times 40$. (b) Percentage of $\mathrm{Ki}^{+} 7^{+} \mathrm{INS}^{+}$cells and (c) beta cell size $\left(\mu \mathrm{m}^{2}\right)$. A total of $43.85 \pm 4.83$ islets were analysed for Ki67 expression and beta cell size ( $n=5-6$ mice/group). (d) Confocal microscopy images of islets double immunostained with antibodies against p-S6 (green) and INS (red); scale bars, $50 \mu \mathrm{m}$; magnification $\times 40$. (e) Percentage of $\mathrm{p}$ $\mathrm{S}^{+}{ }^{+} \mathrm{INS}^{+}$cells. All islets within two pancreatic sections per mouse $(n=4$ mice/group) were analysed, with each section being generated every 200

THP1 protein levels, along with increased serotonin secretion $(p<0.05)$ vs controls (Fig. 6a,b,d-f), we studied its direct effects on the serotonergic system in isolated islets. As shown in Fig. 7a,b, treatment with aripiprazole for $24 \mathrm{~h}$ appeared to increase serotonin and TPH1 protein levels vs controls.

Finally, we studied whether serotonin mediates the effects of aripiprazole on mTORC1 activity and beta cell function.
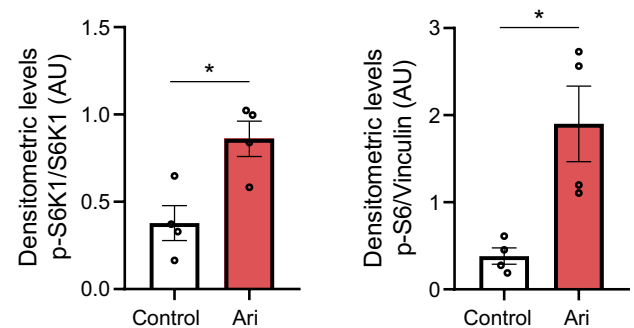

$\mu \mathrm{m}$. A total of $22.83 \pm 1.98$ islets were quantified for $\mathrm{p}$-S6 staining. (f) Islets were incubated with $6 \mu \mathrm{mol} / 1$ aripiprazole (ari) or vehicle $(0.01 \%$ DMSO [control]) for $16 \mathrm{~h}$ and phosphorylation levels of mTOR, S6K1 and S6 were analysed by western blot. Representative blots of mTOR, S6K1 and S6 phosphorylation levels in independent pools of 200-300 islets isolated from $n=4-6$ mice are shown. Quantification of protein levels is also shown ( $n=4$ independent experiments). Data are presented as mean \pm SEM. AU, arbitrary units; ola, olanzapine. ${ }^{*} p<0.05$ vs mice fed a chow diet, analysed by one-way ANOVA test and Bonferroni post hoc test in $(\mathbf{b}, \mathbf{c})$, by Kruskal-Wallis test and Bonferroni post hoc test in (e), or unpaired Student's $t$ test in (f)

Our findings suggest that treatment with serotonin $(100 \mu \mathrm{mol} /$ 1) for $1 \mathrm{~h}$ increased mTORC1 activity, as reflected by apparent increases in mTOR, S6K1 and S6 phosphorylation vs controls (Fig. 7c). Moreover, treatment of islets with serotonin for $24 \mathrm{~h}$ inhibited GSIS vs controls (Fig. 7d), as previously reported [24, 25]. Importantly, co-treatment with aripiprazole and the TPH1 inhibitor PCPA prevented the negative effect of 

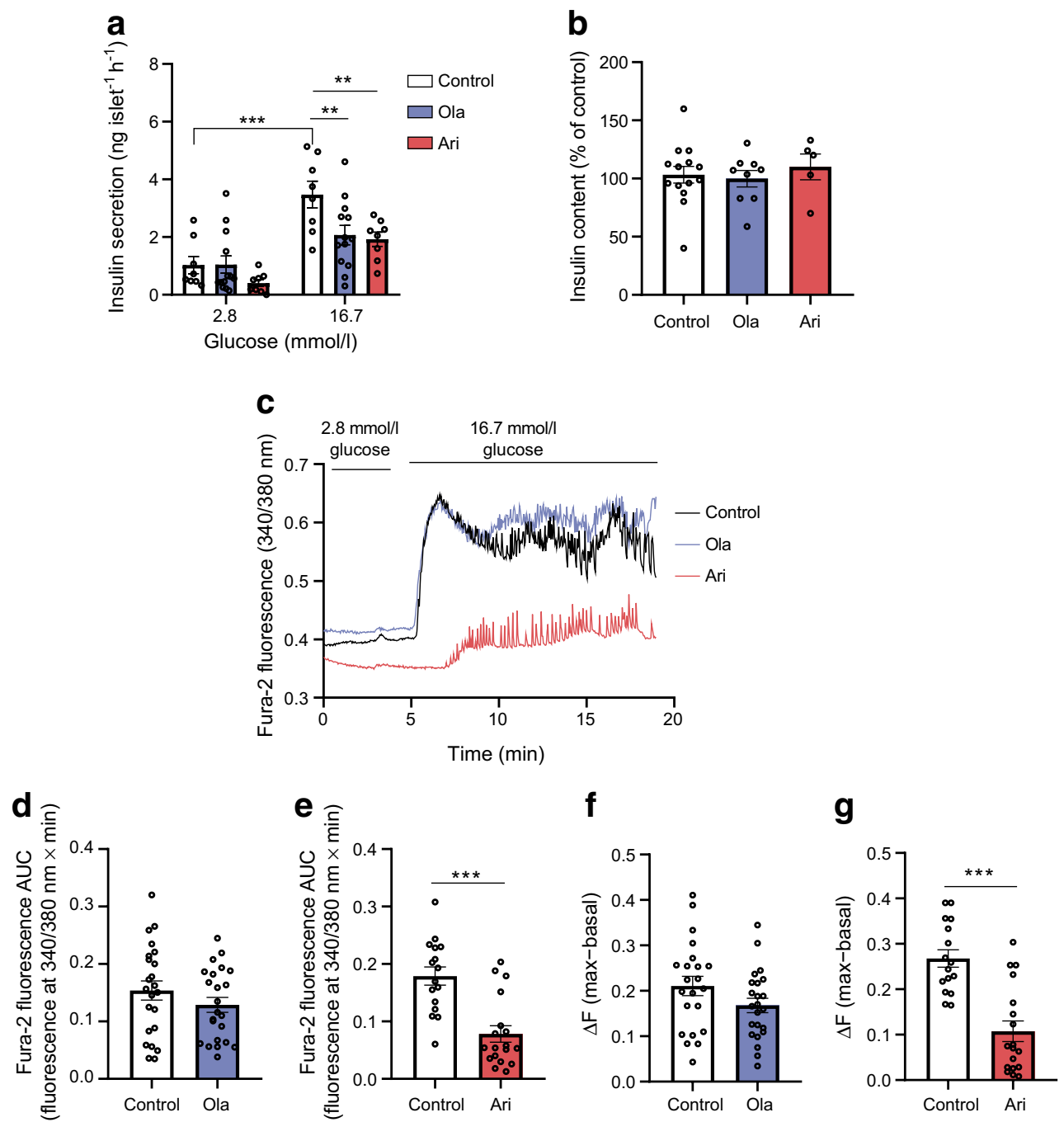

Fig. 4 Effect of ex vivo treatment of pancreatic islets with olanzapine (ola) or aripiprazole (ari) on insulin secretion and $\mathrm{Ca}^{2+}$ signalling. (a) GSIS analysis performed in islets treated with either ola or ari (6 $\mu \mathrm{mol} / \mathrm{l})$ or vehicle $(0.01 \%$ DMSO [control]) for $24 \mathrm{~h}$. We performed 36 technical replicates for each condition and mouse ( $n=8-13$ mice/group). (b) Insulin content in islets. Twenty islets per condition were lysed and the insulin content was measured and normalised to insulin content in control islets. Statistically significant differences were not observed between groups, as determined by one-way ANOVA ( $n=5-14$ mice/group). (c) Representative recordings of Fura- $2 \mathrm{Ca}^{2+}$ fluorescence

in beta cells from islets in response to high glucose concentrations (16.7 $\mathrm{mmol} / \mathrm{l})$ under treatment with vehicle (0.01\% DMSO [control]), $6 \mu \mathrm{mol} / 1$ ola or $6 \mu \mathrm{mol} / 1$ ari. (d, e) Quantification of the AUC of Fura-2 $\mathrm{Ca}^{2+}$ fluorescence per min in vehicle-treated islets vs islets treated with ola (d) or ari (e). (f, g) $\Delta \mathrm{F}$ (maximum [max] $-\mathrm{F}_{\text {basal }}$ ) in control islets vs islets treated with ola (f) or ari $(\mathbf{g})$. In $(\mathbf{d}-\mathbf{g})$ a total of 16-25 islets from $n=6$ mice were used in each condition. Data are presented as mean \pm SEM. $* * p<0.01, * * * p<0.001$ vs control, by two-way ANOVA and Bonferroni post hoc test in (a), Student's $t$ test in (d, f, g) or MannWhitney $U$ test in (e)

aripiprazole on insulin secretion (Fig. 7e). Collectively, we suggest that aripiprazole increases serotonin biosynthesis and secretion in islets and mediates mTORC1 activation and, probably, beta cell hypertrophy, while impairing insulin secretion.

\section{Discussion}

This study provides novel findings on the effect of the SGAs olanzapine and aripiprazole in inducing glucose intolerance and reducing insulin secretion. We demonstrate that

aripiprazole modulates the serotonergic system in islets, increasing $\mathrm{mTOR} / \mathrm{S} 6$ phosphorylation, as well as elevating TPH1 expression and serotonin production in beta cells. By contrast, the effects of olanzapine on insulin secretion seem to be independent of the serotonergic system. Since type 2 diabetes develops gradually through life, and chronic medication is needed to tackle schizophrenia, we analysed the metabolic disturbances in female mice treated with these two chemically unrelated SGAs via supplementation in the diet over 6 months. To our knowledge, this is the first preclinical study in rodents to report the metabolic outcomes of long-term administration of olanzapine and aripiprazole that focuses on islet function. 
a

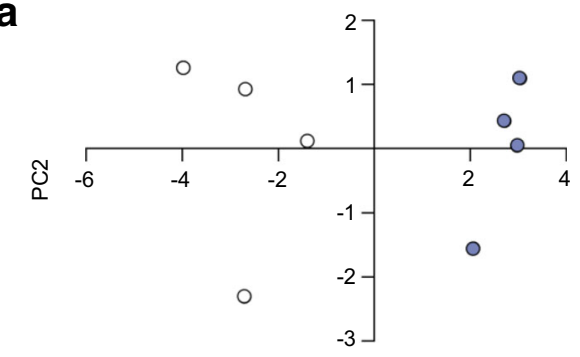

PC1 b
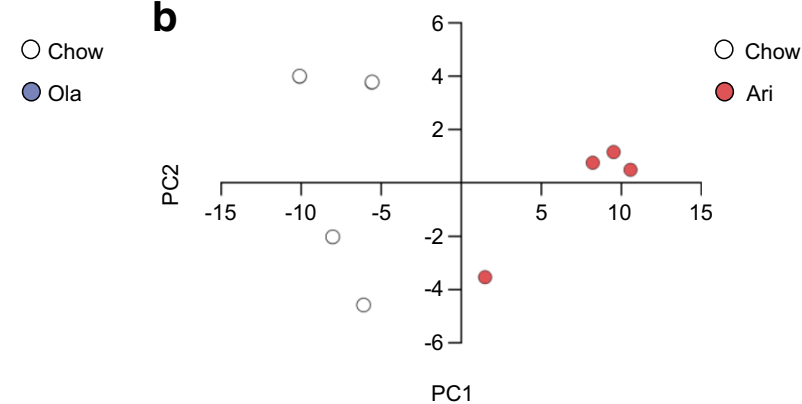

C

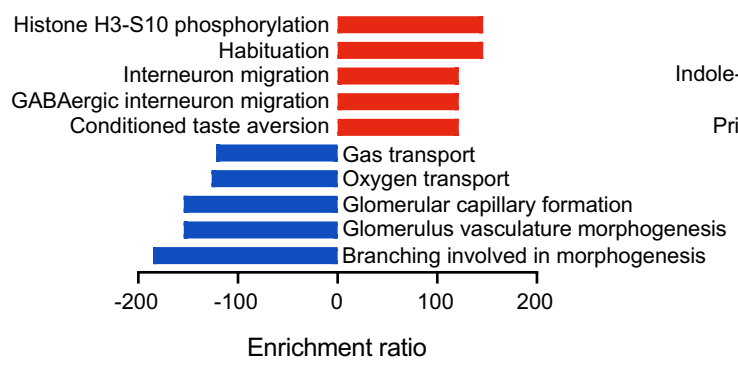

d

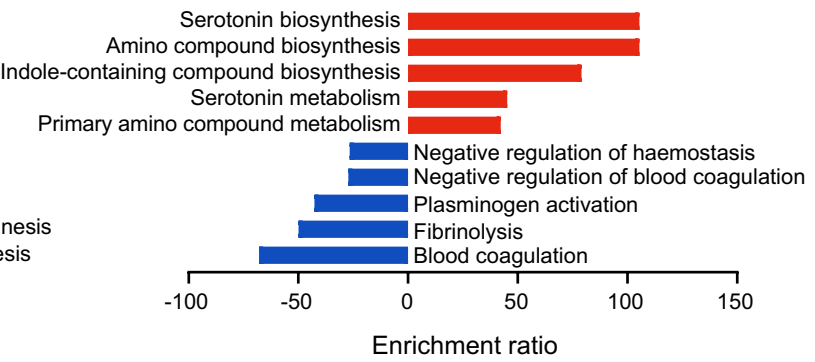

f

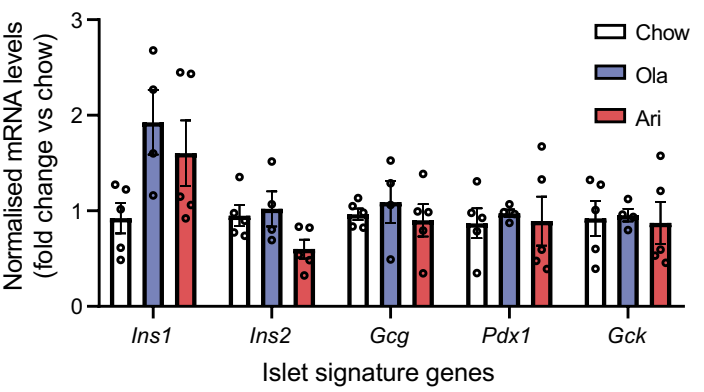

upregulated genes shown in red. (f) Analysis of common islet-related genes by RT-qPCR. Expression was normalised to the mean $\mathrm{C}_{\mathrm{t}}$ values of two housekeeping genes (Actb and Gapdh). Each sample contained a pool of 500 islets from $n=4$ mice ( $n=4-5$ samples/group). Data are presented as mean \pm SEM. Statistical significance differences were not observed in (f), as analysed by the Kruskal-Wallis test, or one-way ANOVA and Bonferroni post hoc test. GABA, $\gamma$-aminobutyric acid; $\mathrm{PC}$, principal component

patients treated for longer than 12 months, but this has not been the case for aripiprazole [29]. Yet, recent findings point to a mean $6-7 \%$ gain in body weight in young people receiving aripiprazole [30]. Remarkably, visceral adiposity was increased in mice treated with either drug, although the effect with aripiprazole treatment was more robust. In studies of olanzapine therapy, increased adiposity has been reported both concomitantly with [31], and also independently from [32] weight gain. Altogether, our results suggest that both olanzapine and aripiprazole increase adiposity, irrespective of the degree of weight gain. Of note, as schizophrenia, per 
a

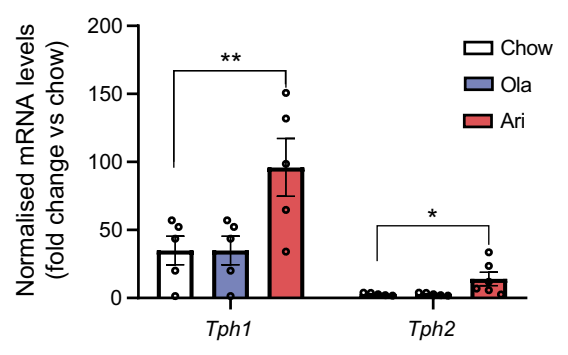

5-HT biosynthetic genes

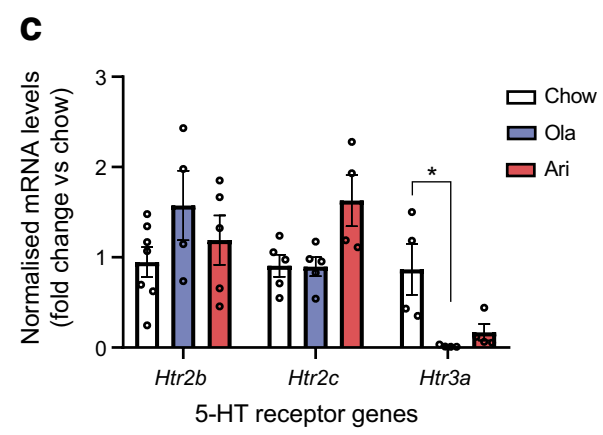

e
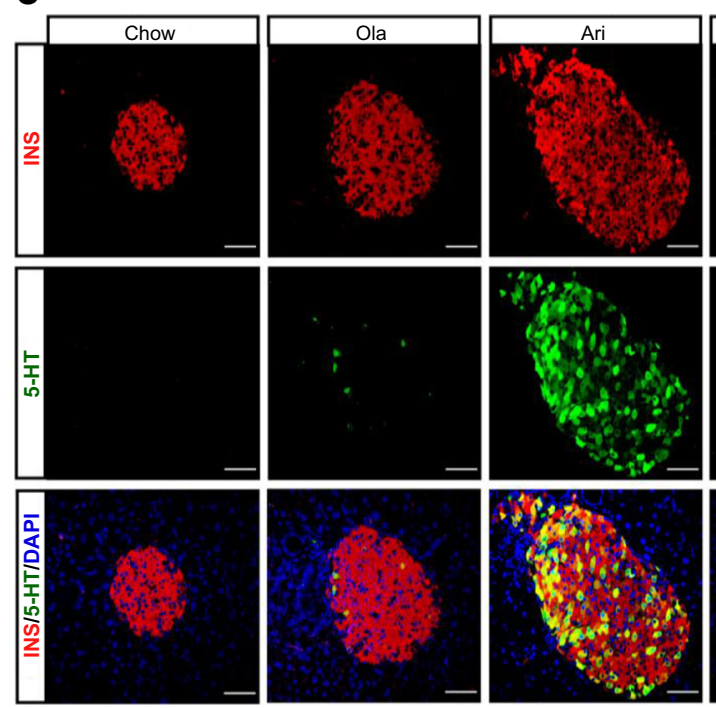

b

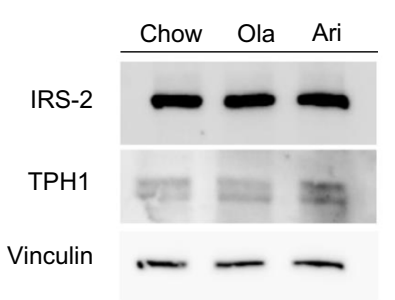

d

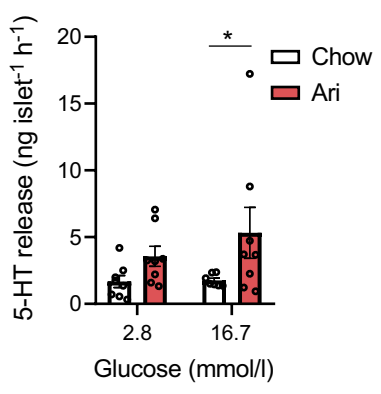

Fig. 6 Effect of olanzapine (ola) or aripiprazole (ari) treatment on the expression of serotonergic system-related genes and serotonin (5-HT) levels in islets from female mice after 6 months of treatment with antipsychotic drug-supplemented diets. (a) RT-qPCR analysis of 5-HT-related biosynthetic gene expression normalised against median $\mathrm{C}_{\mathrm{t}}$ values of two housekeeping genes (Actb and Gapdh). Each sample contained a pool of 500 islets from $n=4$ mice (Tph1 analysis: $n=5$ samples/group; Tph 2 analysis: $n=5$ samples for control, $n=5$ samples for ola-treated mice and $n=6$ samples for ari-treated mice). (b) TPH1 protein expression by western blot. Each sample contained a pool of 500 islets from $n=3$ mice/group (control mice, or mice treated with ola or ari for 6 months). Vinculin and IRS-2 were used as loading controls. (c) mRNA expression of 5-HT receptor genes, analysed by RT-qPCR. Each sample contained a pool of 500 islets from $n=4$ mice ( $n=4-7$ samples/group). (d) 5 -HT

se, concurs with metabolic derangements [33], the metabolic side effects of SGAs are likely to be more severe in the context
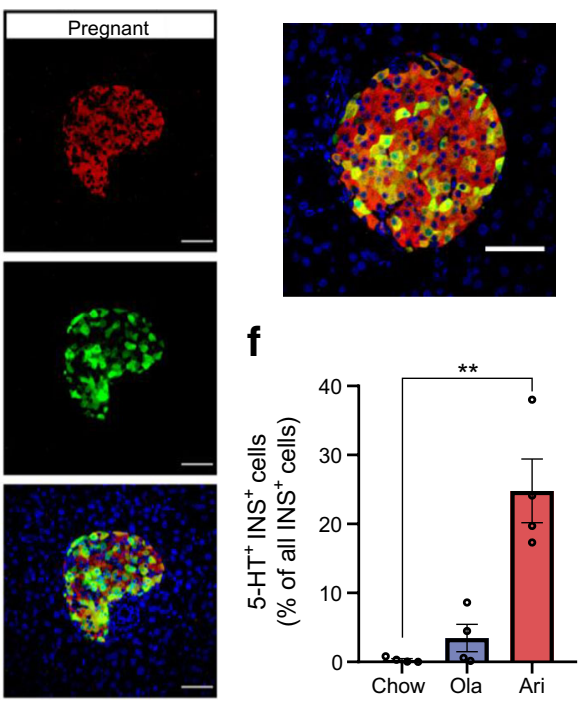

release was measured by ELISA in the culture medium of islets previously challenged with $16.7 \mathrm{mmol} / 1$ glucose ( $n=8 \mathrm{mice} /$ group). (e) Representative images of pancreatic islets expressing insulin (INS; red) and 5-HT (green), captured with confocal microscopy; scale bars, $50 \mu \mathrm{m}$; magnification $\times 40$. A higher magnification of an islet co-expressing INS and 5-HT after ari treatment is also shown; scale bar, $50 \mu \mathrm{m}$; magnification $\times 40$. (f) Percentage of $5-\mathrm{HT}^{+} \mathrm{INS}^{+}$cells. All islets within two pancreatic sections per mouse ( $n=4$ mice/group) were analysed, with each section being generated every $200 \mu \mathrm{m}$. A total of $26.25 \pm 3.28$ islets were quantified for 5 -HT expression. Data are presented as mean \pm SEM. $* p<0.05, * * p<0.01$ vs mice fed a chow diet, analysed by one-way ANOVA and Bonferroni post hoc test in (a, c), two-way ANOVA and Bonferroni post hoc test in (d) or Kruskal-Wallis test (f)

of this disease. Also, although female patients are more susceptible to changes in glucose metabolism following 
a

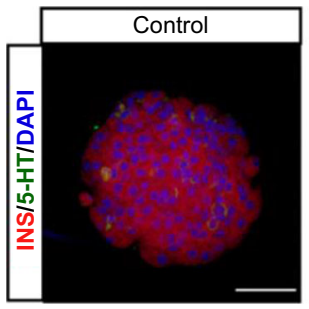

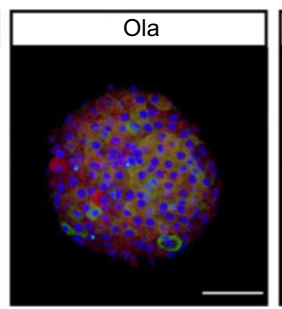

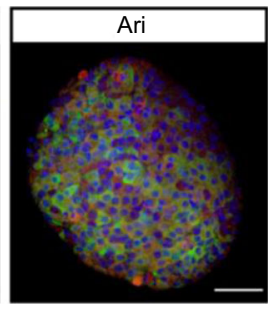

b

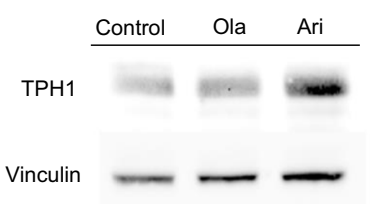

C

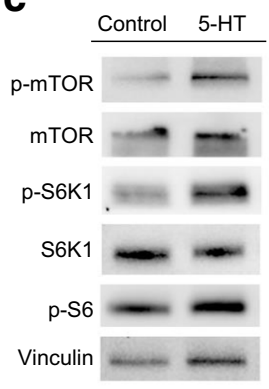

d

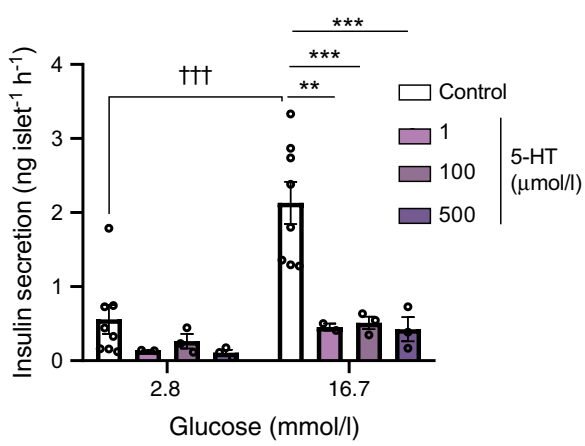

e

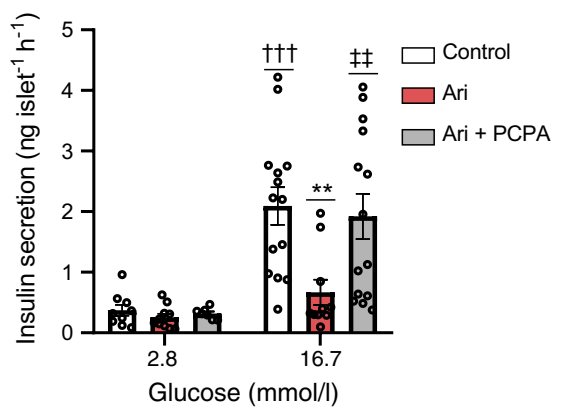

Fig. 7 Effect of ex vivo treatment of pancreatic islets with olanzapine (ola) or aripiprazole (ari) on serotonin (5-HT) expression. (a) In toto islets were immunostained for insulin (INS; red) and 5-HT (green) after ex vivo treatment with ola or ari for $24 \mathrm{~h}$. Images were captured by confocal microscopy; scale bar, $50 \mu \mathrm{m}$; magnification $\times 40$. (b) TPH1 protein expression analysed by western blot (using vinculin as a loading control) after ex vivo treatment of islets with ola or ari for $24 \mathrm{~h}$. Each sample (control [untreated islets], or islets treated ex vivo with ola or ari) contained a pool of 500 islets from $n=12$ mice. (c) Islets were incubated with $100 \mu \mathrm{mol} / 15-\mathrm{HT}$ for $1 \mathrm{~h}$ and phosphorylation levels of mTOR, S6K1 and S6 were analysed by western blot. Each sample (control [untreated islets] or islets treated ex vivo with 5-HT) contained a pool

SGA exposure [6], the current study is a single-sex study, a limitation that needs to be considered for its translatability.

Female mice treated with olanzapine or aripiprazole developed glucose intolerance that was associated with insulin resistance in aripiprazole-treated mice. However, we cannot exclude that longer treatments or more sensitive assays to assess insulin sensitivity, such as the euglycaemichyperinsulinaemic clamp, would reveal greater effects on blood glucose levels and insulin sensitivity. A step further, this is the first study to unravel a unique effect of aripiprazole in interfering with glucose-regulated $\mathrm{Ca}^{2+}$ signalling, whereas olanzapine likely inhibits insulin secretion through a mechanism distal to $\mathrm{Ca}^{2+}$ entry into the beta cell. Of interest, while the GSIS test addresses insulin secretion exclusively, we cannot exclude alterations in hepatic insulin clearance or the beta cell insulin-degrading enzyme, both of which impair insulin secretion [34].

Notably, mice treated with the SGAs had larger islets, particularly the aripiprazole-treated group, in which beta cell mass was twofold higher than that of the control group. In of 200 islets from $n=6$ mice. (d) Ex vivo GSIS in pancreatic islets after $24 \mathrm{~h}$ of treatment with 5-HT. We performed 3-6 technical replicates for each condition and mouse ( $n=2-3$ mice for serotonin, $n=8$ mice for control). (e) Ex vivo GSIS in pancreatic islets after $24 \mathrm{~h}$ of treatment of ari $(6 \mu \mathrm{mol} / 1)$ and PCPA $(10 \mu \mathrm{mol} / \mathrm{l})$. Experiments were performed with at least 3-6 technical replicates per condition in pools of islets from $n=10-14$ mice ( $n=3$ independent experiments). $* * p<0.01, * * * p<0.001$ vs control islets stimulated with $16.7 \mathrm{mmol} / 1$ glucose; ${ }^{\dagger \dagger} p<0.001 \mathrm{vs}$ control islets stimulated with $2.8 \mathrm{mmol} / 1$ glucose; ${ }^{*} p<0.01$ vs islets treated with ari and stimulated with $16.7 \mathrm{mmol} / \mathrm{l}$ glucose; analysed by twoway ANOVA and Bonferroni post hoc test

obesity and pregnancy, beta cell expansion is associated with enhanced insulin secretion, which compensates for insulin resistance. On the contrary, aripiprazole impairs insulin secretion despite beta cell expansion, indicating that increased beta cell mass, per se, is not sufficient to overcome beta cell dysfunction. The apparent paradoxical effects on mass and function were more prominent in aripiprazole-treated mice in which doubling of beta cell mass was associated with blunted insulin response.

Treatment with SGAs did not affect beta cell proliferation, which remained low, as previously reported in middle-aged mice [20]. However, a compensatory proliferative response might be expected at an earlier stage of the treatment. On the contrary, we found increased beta cell size in islets from both groups of SGA-treated mice, as compared with controls, which might explain the islet size expansion observed at the end of the treatment. Activation of mTORC1 signalling, which increases islet hypertrophy, has been suggested to be involved in the compensatory beta cell expansion during insulin resistance [35]. Our results showed islet hypertrophy in 
aripiprazole-treated mice together with increased p-S6 staining in beta cells, an effect reinforced by increased phosphorylation of mTOR and its downstream targets S6K1 and S6 in islets treated ex vivo with this SGA. Thus, the increased islet size and beta cell mass by aripiprazole might be mediated via mTORC1/S6. By contrast, S6 phosphorylation was not increased by olanzapine. At the molecular level, the differential ability of each drug to induce mTORC1/S6 activity or, alternatively, other mechanisms, such as the Hippo pathway [36], might also be implicated in the islet hypertrophy observed with olanzapine. Also, lower mTORC1 activation in olanzapine-treated mice could be due to a more subtle (non-significant) increase in insulin intolerance. It is noteworthy that we found greater (although not significant) differences in insulin granule maturation in olanzapine-treated mice vs the control group, manifested by a decrease and increase in mature and empty granules, respectively (both $p=0.09$ ), which deserves further investigation. Additionally, olanzapinetreated mice had higher alpha cell mass, pointing to potential pancreatic alterations beyond beta cells.

The complexity of the dopaminergic and serotonergic systems in pancreatic islets, which regulate insulin secretion $[10,37]$, together with the broad spectrum of dopamine/ serotonin receptors targeted by SGAs, makes it difficult to determine whether a specific receptor mediates the effects of a particular SGA or if the final outcome results from signalling pathways activated by multiple receptors. Transcriptomic analysis of pancreatic islets did not show changes in genes related to dopamine signalling, but revealed changes in genes regulating serotonin synthesis. Aripiprazole upregulated $T p h 1$ and Tph 2 genes, and the induction of Tph1 mRNA and TPH1 protein levels (the rate-limiting isoform for serotonin biosynthesis) was associated with increased serotonin content and release in islets from aripiprazole-treated mice. These results were supported by: (1) the ex vivo treatment of islets with aripiprazole, which similarly resulted in increased TPH1 expression; (2) the decrease in insulin secretion in islets treated with serotonin that, like aripiprazole, activated mTORC1/ S6 signalling; (3) and the recovery of GSIS in islets treated ex vivo with aripiprazole together with a TPH1 inhibitor, pointing to serotonin-mediated inhibition of insulin secretion by this SGA. Our findings are in agreement with a recent study showing that Sirtuin 3 deficiency in beta cells increased Tph1 expression, along with impairment of GSIS in obese mice [38].

Transcriptomic analysis also showed that olanzapine downregulated the expression of Htr $3 a$, which encodes a serotonin receptor, in islets, potentially playing a role in the impairment of insulin secretion by this SGA, as previously reported $[39,40]$. Notably, changes in serotonin receptor expression were found in $d b / d b$ mice, which exhibited increased expression of Htr2c [41]. So far, the role of serotonin signalling in beta cell expansion has been described only in pregnancy $[22,23]$ and the perinatal period [42]. Recent studies suggest that increased serotonin production could affect whole-body glucose homeostasis and adiposity [43]. In the context of tumour growth, serotonin increases mTORC1 activity in hepatocellular carcinoma [44], reinforcing a possible link between serotonin and mTORC1/S6 signalling. Because serotonin is also a strong paracrine regulator of alpha cell activity [45], additional effects of aripiprazole on alpha cells functionality cannot be ruled out.

In summary, we have identified alterations in islet plasticity and insulin secretion in female mice treated with the SGAs olanzapine and aripiprazole, with important translational implications. In the case of aripiprazole, in which the serotonergic system was activated, specific TPH1 inhibitors that do not cross the blood-brain barrier could be used to prevent intra-islet and peripheral serotonin dysregulation without affecting serotonin levels in the brain [46].

Supplementary Information The online version contains peer-reviewed but unedited supplementary material available at https://oi.org/10.1007/ s00125-021-05630-0.

Acknowledgements The authors would like to thank M. Belinchón (IIBm, CSIC, Madrid, Spain) for the technical assistance with confocal microscopy. We also acknowledge all members of ÁMV's laboratory for helpful discussions. Some of the data were presented as an abstract at the 55th EASD Annual Meeting in 2019.

Data availability Data presented in this manuscript are available upon request from the corresponding author.

Funding Open Access funding provided thanks to the CRUE-CSIC agreement with Springer Nature. This work was funded by H2020 Marie Sklodowska-Curie ITN-TREATMENT (Grant Agreement 721236, European Commission). We also acknowledge grants RTI2018-094052-B-100/ AEI/10.13039/501100011033 (Ministerio de Ciencia e Innovación y Fondo Europeo de Desarrollo Regional [FEDER]) and S2017/BMD-3684 (Comunidad de Madrid, Spain), and grants from Fundación Ramón Areces (Spain) and CIBERDEM (ISCIII, Spain).

Authors' relationships and activities The authors declare that there are no relationships or activities that might bias, or be perceived to bias, their work.

Contribution statement The study was designed by DG and ÁMV. Islet isolation, data acquisition, and analysis and interpretation of batch incubations were performed by DG. Immunohistochemistry, immunofluorescence and TEM analyses were performed by DG and PV. Gene expression analysis was performed by MRR, JCC and DG. $\mathrm{Ca}^{2+}$ experiments and analysis were performed by DG, ET and IQ. MM, ABH, MV and BT assisted with islets studies and data interpretation. GTTs, in vivo GSIS and ITTs were performed and analysed by DG, ÁMV and VF. Concentrations of antipsychotic drugs in plasma were determined and analysed by DK, PZ and FAS. DG, PV and ÁMV wrote the first draft of the manuscript. MRR, ET, MM, VF, ABH, DK, PZ, JCC, FAS, MV, IQ and BT critically revised the manuscript for important intellectual content. GL co-designed the study, collected and interpreted the data and critically revised the manuscript. All authors gave final approval of 
the manuscript and gave consent to its publication. ÁMV coordinated the study and is the guarantor of this work.

Open Access This article is licensed under a Creative Commons Attribution 4.0 International License, which permits use, sharing, adaptation, distribution and reproduction in any medium or format, as long as you give appropriate credit to the original author(s) and the source, provide a link to the Creative Commons licence, and indicate if changes were made. The images or other third party material in this article are included in the article's Creative Commons licence, unless indicated otherwise in a credit line to the material. If material is not included in the article's Creative Commons licence and your intended use is not permitted by statutory regulation or exceeds the permitted use, you will need to obtain permission directly from the copyright holder. To view a copy of this licence, visit http://creativecommons.org/licenses/by/4.0/.

\section{References}

1. Liu MZ, He HY, Luo JQ et al (2018) Drug-induced hyperglycaemia and diabetes: pharmacogenomics perspectives. Arch Pharm Res 41(7):725-736. https://doi.org/10.1007/s12272018-1039-x

2. Vancampfort D, Wampers M, Mitchell AJ et al (2013) A metaanalysis of cardio-metabolic abnormalities in drug naïve, firstepisode and multi-episode patients with schizophrenia versus general population controls. World Psychiatry 12(3):240-250. https://doi.org/10.1002/wps.20069

3. Vancampfort D, Correll CU, Galling B et al (2016) Diabetes mellitus in people with schizophrenia, bipolar disorder and major depressive disorder: a systematic review and large scale meta-analysis. World Psychiatry 15(2):166-174. https://doi.org/10.1002/ wps. 20309

4. Nielsen J, Skadhede S, Correll CU (2010) Antipsychotics associated with the development of type 2 diabetes in antipsychotic-naive schizophrenia patients. Neuropsychopharmacology 35(9):19972004. https://doi.org/10.1038/npp.2010.78

5. Rajkumar AP, Horsdal HT, Wimberley T et al (2017) Endogenous and Antipsychotic-Related Risks for Diabetes Mellitus in Young People With Schizophrenia: A Danish Population-Based Cohort Study. Am J Psychiatry 174(7):686-694. https://doi.org/10.1176/ appi.ajp.2016.16040442

6. Castellani LN, Costa-Dookhan KA, McIntyre WB et al (2019) Preclinical and Clinical Sex Differences in Antipsychotic-Induced Metabolic Disturbances: A Narrative Review of Adiposity and Glucose Metabolism. J Psychiatr Brain Sci 4(4):e190013. https:// doi.org/10.20900/jpbs.20190013

7. Mauri MC, Paletta S, Di Pace C et al (2018) Clinical Pharmacokinetics of Atypical Antipsychotics: An Update. Clin Pharmacokinet 57(12):1493-1528. https://doi.org/10.1007/ s40262-018-0664-3

8. Grajales D, Ferreira V, Valverde AM (2019) Second-Generation Antipsychotics and Dysregulation of Glucose Metabolism: Beyond Weight Gain. Cells 8(11):1336. https://doi.org/10.3390/ cells 8111336

9. Melkersson K, Khan A, Hilding A, Hulting AL (2001) Different effects of antipsychotic drugs on insulin release in vitro. Eur Neuropsychopharmacol 11(5):327-332. https://doi.org/10.1016/ S0924-977X(01)00108-0

10. Cataldo Bascuñan LR, Lyons C, Bennet H, Artner I, Fex M (2019) Serotonergic regulation of insulin secretion. Acta Physiol 225(1): e13101. https://doi.org/10.1111/apha.13101
11. Gonzalez-Rodriguez A, Santamaria B, Mas-Gutierrez JA et al (2015) Resveratrol treatment restores peripheral insulin sensitivity in diabetic mice in a sirt1-independent manner. Mol Nutr Food Res 59(8):1431-1442. https://doi.org/10.1002/mnfr.201400933

12. Koller D, Zubiaur P, Saiz-Rodríguez M, Abad-Santos F, Wojnicz A (2019) Simultaneous determination of six antipsychotics, two of their metabolites and caffeine in human plasma by LC-MS/MS using a phospholipid-removal microelution-solid phase extraction method for sample preparation. Talanta 198:159-168. https://doi. org/10.1016/j.talanta.2019.01.112

13. Ribas-Aulinas F, Ribo S, Parra-Vargas M et al (2021) Neonatal overfeeding during lactation rapidly and permanently misaligns the hepatic circadian rhythm and programmes adult NAFLD. Mol Metab 45:101162. https://doi.org/10.1016/j.molmet.2021.101162

14. Carter JD, Dula SB, Corbin KL, Wu R, Nunemaker CS (2009) A Practical Guide to Rodent Islet Isolation and Assessment. Biol Proced Online 11(1):3. https://doi.org/10.1007/s12575-009-9021-0

15. Téllez N, Montanya E (2020) Determining Beta Cell Mass, Apoptosis, Proliferation, and Individual Beta Cell Size in Pancreatic Sections. Methods Mol Biol 2128:313-337. https:// doi.org/10.1007/978-1-0716-0385-7_21

16. Bray NL, Pimentel H, Melsted P, Pachter L (2016) Near-optimal probabilistic RNA-seq quantification. Nat Biotechnol 34(5):525527. https://doi.org/10.1038/nbt.3519

17. Love MI, Huber W, Anders S (2014) Moderated estimation of fold change and dispersion for RNA-seq data with DESeq2. Genome Biol 15(12):550. https://doi.org/10.1186/s13059-014-0550-8

18. Liao Y, Wang J, Jaehnig EJ, Shi Z, Zhang B (2019) WebGestalt 2019: gene set analysis toolkit with revamped UIs and APIs. Nucleic Acids Res 47(W1):W199-W205. https://doi.org/10.1093/ nar/gkz401

19. Liu X, Feng X, Deng C, Liu L, Zeng Y, Hu C-H (2020) Brown adipose tissue activity is modulated in olanzapine-treated young rats by simvastatin. BMC Pharmacol Toxicol 21(1):48. https://doi. org/10.1186/s40360-020-00427-0

20. Rankin MM, Kushner JA (2009) Adaptive beta-cell proliferation is severely restricted with advanced age. Diabetes 58(6):1365-1372. https://doi.org/10.2337/db08-1198

21. Riahi Y, Israeli T (2018) Inhibition of mTORC1 by ER stress impairs neonatal $\beta$-cell expansion and predisposes to diabetes in the Akita mouse. eLife 7:e38472. https://doi.org/10.7554/eLife. 38472

22. Kim H, Toyofuku Y, Lynn FC et al (2010) Serotonin regulates pancreatic beta cell mass during pregnancy. Nat Med 16(7):804. https://doi.org/10.1038/nm.2173

23. Schraenen A, Lemaire K, de Faudeur G et al (2010) Placental lactogens induce serotonin biosynthesis in a subset of mouse beta cells during pregnancy. Diabetologia 53(12):2589-2599. https:// doi.org/10.1007/s00125-010-1913-7

24. Cataldo LR, Mizgier ML, Bravo Sagua R et al (2017) Prolonged activation of the Htr2b serotonin receptor impairs glucose stimulated insulin secretion and mitochondrial function in MIN6 cells. PLoS One 12(1):e0170213. https://doi.org/10.1371/journal.pone. 0170213

25. Zawalich WS, Tesz GJ, Zawalich KC (2004) Effects of prior 5hydroxytryptamine exposure on rat islet insulin secretory and phospholipase C responses. Endocrine 23(1):11-16. https://doi.org/10. 1385/ENDO:23:1:11

26. Wang Y, Wang D, Chen Y, Fang X, Yu L, Zhang C (2020) A Novel Synthetic Interfering Peptide Tat-3L4F Attenuates Olanzapine-Induced Weight Gain Through Disrupting Crosstalk Between Serotonin Receptor 2C and Protein Phosphatase and Tensin Homolog in Rats. Int J Neuropsychopharmacol. https:// doi.org/10.1093/ijnp/pyaa001

27. Chen X, Yu Y, Zheng P et al (2020) Olanzapine increases AMPKNPY orexigenic signaling by disrupting H1R-GHSR1a interaction 
in the hypothalamic neurons of mice. Psychoneuroendocrinology 114:104594. https://doi.org/10.1016/j.psyneuen.2020.104594

28. Lord CC, Wyler SC, Wan R et al (2017) The atypical antipsychotic olanzapine causes weight gain by targeting serotonin receptor $2 \mathrm{C}$. J Clin Invest 127(9):3402-3406. https://doi.org/10.1172/jci93362

29. Pillinger T, McCutcheon RA, Vano L et al (2020) Comparative effects of 18 antipsychotics on metabolic function in patients with schizophrenia, predictors of metabolic dysregulation, and association with psychopathology: a systematic review and network metaanalysis. Lancet Psychiatry 7(1):64-77. https://doi.org/10.1016/ s2215-0366(19)30416-x

30. Shymko G, Grace T, Jolly N et al (2021) Weight gain and metabolic screening in young people with early psychosis on long acting injectable antipsychotic medication (aripiprazole vs paliperidone). Early Interve Psychiatry 15(4):787-793. https://doi.org/10.1111/ eip. 13013

31. Horska K, Ruda-Kucerova J, Babinska Z et al (2016) Olanzapinedepot administration induces time-dependent changes in adipose tissue endocrine function in rats. Psychoneuroendocrinology 73: 177-185. https://doi.org/10.1016/j.psyneuen.2016.07.218

32. Minet-Ringuet J, Even PC, Valet P et al (2007) Alterations of lipid metabolism and gene expression in rat adipocytes during chronic olanzapine treatment. Mol Psychiatry 12(6):562-571. https://doi. org $/ 10.1038 /$ sj.mp. 4001948

33. Pillinger T, Beck K, Gobjila C, Donocik JG, Jauhar S, Howes OD (2017) Impaired Glucose Homeostasis in First-Episode Schizophrenia: A Systematic Review and Meta-analysis. JAMA Psychiatry 74(3):261-269. https://doi.org/10.1001/jamapsychiatry. 2016.3803

34. Fernández-Díaz CM, Merino B, López-Acosta JF et al (2019) Pancreatic $\beta$-cell-specific deletion of insulin-degrading enzyme leads to dysregulated insulin secretion and $\beta$-cell functional immaturity. Am J Phys Endocrinol Metab 317(5):E805-e819. https://doi. org/10.1152/ajpendo.00040.2019

35. Fraenkel M, Ketzinel-Gilad M, Ariav Y et al (2008) mTOR inhibition by rapamycin prevents beta-cell adaptation to hyperglycemia and exacerbates the metabolic state in type 2 diabetes. Diabetes 57(4):945-957. https://doi.org/10.2337/db07-0922

36. Ardestani A, Maedler K (2018) The Hippo Signaling Pathway in Pancreatic $\beta$-Cells: Functions and Regulations. Endocr Rev 39(1): 21-35. https://doi.org/10.1210/er.2017-00167
37. Farino ZJ, Morgenstern TJ, Maffei A et al (2019) New roles for dopamine D2 and D3 receptors in pancreatic beta cell insulin secretion. Mol Psychiatry 25:2070-2085. https://doi.org/10.1038/ s41380-018-0344-6

38. Ming X, Chung ACK, Mao D et al (2021) Pancreatic Sirtuin 3 Deficiency Promotes Hepatic Steatosis by Enhancing 5Hydroxytryptamine Synthesis in Mice With Diet-Induced. Obesity 70(1):119-131. https://doi.org/10.2337/db20-0339

39. Ohara-Imaizumi M, Kim H, Yoshida M et al (2013) Serotonin regulates glucose-stimulated insulin secretion from pancreatic $\beta$ cells during pregnancy. Proc Natl Acad Sci 110(48):19420-19425

40. Kim K, Oh C-M, Ohara-Imaizumi M et al (2015) Functional role of serotonin in insulin secretion in a diet-induced insulin-resistant state. Endocrinology 156(2):444-452. https://doi.org/10.1210/en. 2014-1687

41. Zhang Q, Zhu Y, Zhou W, Gao L, Yuan L, Han X (2013) Serotonin receptor 2C and insulin secretion. PLoS One 8(1):e54250. https:// doi.org/10.1371/journal.pone.0054250

42. Moon JH, Kim YG, Kim K et al (2020) Serotonin Regulates Adult $\beta$-Cell Mass by Stimulating Perinatal $\beta$-Cell Proliferation. Diabetes 69(2):205-214. https://doi.org/10.2337/db19-0546

43. Choi W, Moon JH, Kim H (2020) Serotonergic regulation of energy metabolism in peripheral tissues. J Endocrinol 245(1):R1-r10. https://doi.org/10.1530/joe-19-0546

44. Soll C, Jang JH, Riener MO et al (2010) Serotonin promotes tumor growth in human hepatocellular cancer. Hepatology 51(4):1244 1254. https://doi.org/10.1002/hep.23441

45. Almaça J, Molina J, Menegaz D et al (2016) Human Beta Cells Produce and Release Serotonin to Inhibit Glucagon Secretion from Alpha Cells. Cell Rep 17(12):3281-3291. https://doi.org/10.1016/j. celrep.2016.11.072

46. Betari N, Sahlholm K, Ishizuka Y, Teigen K, Haavik J (2020) Discovery and biological characterization of a novel scaffold for potent inhibitors of peripheral serotonin synthesis. Future Med Chem 12(16):1461-1474. https://doi.org/10.4155/fmc-2020-0127

Publisher's note Springer Nature remains neutral with regard to jurisdictional claims in published maps and institutional affiliations. 